Received: 2014.07.16 Accepted: 2014.08.25 Published: 2015.01 .02

\title{
Delayed Bottom-Up and Amended Simple Method of Dosing with Once-Daily Tacrolimus Application to Achieve Stable Trough Levels in Liver Transplantation
}

Authors' Contribution: Study Design A Data Collection B Statistical Analysis C Data Interpretation D Manuscript Preparation E Literature Search F Funds Collection $G$

\author{
ABCDEF Andreas A. Schnitzbauer \\ ABDF Ceylan Ayik \\ AD Frank Ulrich \\ $A D$ Wolf O. Bechstein \\ ABCDEF
}

Department of General and Visceral Surgery, Frankfurt University Hospitals, Goethe University Frankfurt/Main, Frankfurt/Main, Germany
Corresponding Author: Source of support:

Background: Tacrolimus once-daily formulation (TaCOD) was introduced as an alternative to twice-daily formulations de novo. Dosing recommendations range between 0.1 to $0.2 \mathrm{mg} / \mathrm{kg}$ BW/d.

Material/Methods: Amended dosing with a simple bottom-up de novo algorithm is presented. Primary outcome measure was feasibility of establishing adequate target trough levels and avoidance of over-immunosuppression, with adequate safety and efficacy after liver transplantation (LT).

Results: $\quad$ TacOD was given to 101 patients. Standard steroid-free immunosuppression consisted of MMF 2 g/d, basiliximab $20 \mathrm{mg}$ on day 0 and 4, and delayed bottom-up IS with TacOD starting with $1 \mathrm{mg} / \mathrm{d}$ and doubling the dosage every day until target trough levels of 5 to $8 \mathrm{ng} / \mathrm{ml}$ were reached. By day 7 after LT, all except 3 patients had received TacOD. The earliest time point of introduction was day 2. A median of $9 \mathrm{mg} / \mathrm{d}$ (range: 0 to $25 \mathrm{mg} / \mathrm{d}$ ) of TacOD were necessary to establish the trough levels by day 10 , which was then $5.4 \mathrm{ng} / \mathrm{ml}$ (range: 1.5 to $20 \mathrm{ng} / \mathrm{ml}$ ). Incidence of adverse events (AE), in particular neurological AEs ( $n=3)$, were low. Efficacy failure (acute rejection) was low (4.9\%). Renal function was stable and did not deteriorate under CNI treatment.

Conclusions: This is the first report of bottom-up, amended, and simple dosing of TacOD in LT. The algorithm is feasible, safe, and efficient, avoiding trough level peaks and top-down strategies.

MeSH Keywords: Immunosuppression • Liver Transplantation • Tacrolimus

Abbreviations: $\quad$ AE - adverse event; $\mathbf{A l H}$ - autoimmune hepatitis; ALF - acute liver failure; AUC - area under the curve; BPAR - biopsy-proven acute rejection; CMIA - chemiluminescent immunoassays; CNI - calcineurin inhibitor; $\mathbf{d}$ - days; HCC - hepatocellular carcinoma; GFR - glomerular filtration rate; IQ - interquartile range; LT - liver transplantation; MELD - model of end-stage liver disease; MMF - mycophenolate mofetil; OPTN - organ procurement and transplantation network; PSC - primary sclerosing cholangitis; TacOD - tacrolimus once-daily; Tx - transplantation

Full-text PDF: http://www.annalsoftransplantation.com/abstract/index/idArt/891411

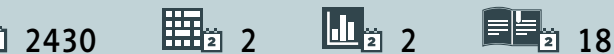




\section{Background}

Tacrolimus once-daily (TacOD) formulation is a drug that was initially introduced as a 1:1 substitute for Tacrolimus twice-daily formulation [1]. The aim was to provide a drug taken only in the morning once to increase patient compliance, which remains to be proven [2]. A recent conversion study in stable liver transplant patients showed feasibility resulting in similar pharmacokinetics and a $30 \%$ reduced requirement in dosing and otherwise a similar adverse effects profile [3,4]. Moreover, the application of TaCOD seems to reduce the variability in 24-h drug exposure [5]. The drug is approved in Europe for de novo immunosuppressive treatment and conversion from the twice-daily to once-daily tacrolimus in stable patients after liver transplantation. Various studies have proven non-inferiority of the safety and efficacy of the drug de novo, especially in renal transplant settings [6]. The FDA recommended usage of $85-125 \%$ of the twice-daily dosage when converting to the once-daily formulation. The package leaflet provided by the marketing authorization holder recommends a dosing of

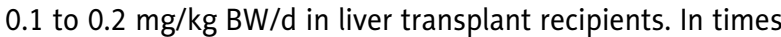
of increasing numbers of patients with high labMELD-scores and renal impairment prior to transplantation, over-immunosuppression should be avoided in the early period after liver transplantation [7-10]. Indeed, the ELITE ReSpECT study published by Neuberger et al. indicated a 5-day delay of tacrolimus with mycophenolate mofetil and induction therapy with IL2-receptor antagonists to be the most promising therapy regarding renal function at 1 year after LT and the lowest incidence of biopsy-proven acute rejections [11]. Other authors have introduced their concept of bottom-up immunosuppres sion with various concepts of de novo CNI delay and/or avoidance [12]. In the following retrospective analysis, we investigated the possibility of an amended and simple method of bottom-up dosing of immunosuppression with TaCOD de novo in patients undergoing LT at Frankfurt University Hospitals, focusing on safely establishing trough levels of 5 to $8 \mathrm{ng} / \mathrm{ml}$.

\section{Material and Methods}

\section{Patient recruitment and outcome measures}

Patients undergoing primary LT at University Hospitals of Frankfurt, Goethe University Frankfurt/Main who received TaCOD as de novo immunosuppressive agent were included in the analysis. Data were extracted retrospectively from electronic patient charts and analyzed accordingly. The local Ethics Committee approved the study. The primary outcome measure was clinical feasibility of an alternative way of slowly increasing dosing TacOD to reach adequate trough levels (5 to $8 \mathrm{ng} / \mathrm{ml}$ ), which avoids relevant trough level peaks in the investigated patient group. Therefore, daily dosages, trough levels, and areas under the curve (AUC) were collected and analyzed. Secondary outcome measures were renal function, liver graft function, and the incidence of biopsy-proven acute rejections (BPAR), as well as neurologic adverse effects and other complications under TaCOD treatment in the early phase (30 days) after LT.

\section{Dosing of once-daily Tacrolimus (TacOD)}

Once-daily formulation of Tacrolimus (TacOD) was introduced as increasing dosage, starting with $1 \mathrm{mg} / \mathrm{d}$, doubling the dosage daily until the intended trough level was reached, and not starting before day 2 after LT until a trough level of 5 to $8 \mathrm{ng} /$ $\mathrm{ml}$ was reached. Trough level measurement was carried out using chemiluminescent immunoassays (CMIA). The rationale for delaying the introduction of TaCOD to different starting days was the existence of patients with impaired renal function, either by acute renal failure or persistent hepatorenal syndrome after LT and patients that have been treated in the ICU prior to transplantation with a high labMELD score (>25).

\section{Subgroup analysis}

Subgroup analyses were performed comparing $\mathrm{HCC}$ with nonHCC indications and patients transplanted with a labMELD score of 25 and higher with those being transplanted with a labMELD score of below 25. Dosing, trough levels, and renal function were compared.

\section{Statistical analysis}

Data are given as median with interquartile ranges (IQR). Data sets are descriptive. Linear regression analysis was performed to correlate AUC and trough levels of TaCOD-application. All analyses were carried out as intention-to-treat analysis including all patients documented. Additionally, various subgroups of patients were analyzed. Statistical analyses were performed using SigmaPlot 12.0 (Systat Software Inc., Richmond, California, USA).

\section{Results}

\section{Immunosuppressive regimen and inclusion of patients}

All 101 patients primarily transplanted at Frankfurt University Hospitals, Goethe-University Frankfurt/Main from 2008 to 2012 were included in this analysis. All received standard immunosuppression with intraoperatively single-shot 500 mg methylprednisolone and $20 \mathrm{mg}$ basiliximab during the anhepatic period, as well as $2 \mathrm{~g} / \mathrm{d}$ of mycophenolate mofetil (MMF) i.v. and bottom-up delayed start of TaCOD as maintenance IS regimen. Basiliximab was administered as additional 20-mg dosage on day 4 after LT. No additional steroids were administered postoperatively, except in 3 patients with autoimmune-hepatitis. 
Table 1. Demographic data and indications.

\begin{tabular}{|c|c|c|c|}
\hline & Median & Minimum & Maximum \\
\hline Age (years) & 55 & 24 & 69 \\
\hline Height (cm) & 172 & 150 & 193 \\
\hline Weight (kg) & 75 & 41 & 125 \\
\hline labMELD & 14 & 6 & 40 \\
\hline Renal replacement therapy prior to $\mathrm{Tx}$ & $\mathrm{N}=8$ & $7.9 \%$ & \\
\hline \multirow{2}{*}{ Sex } & F: 32 & $31.7 \%$ & \\
\hline & M: 69 & $68.3 \%$ & \\
\hline \multirow{6}{*}{ Indications } & $\mathrm{AlH} / \mathrm{PSC}$ & $9.0 \%$ & \\
\hline & ALF and others & $5.0 \%$ & \\
\hline & Alcohol & $10.0 \%$ & \\
\hline & Viral hepatitis & $14.0 \%$ & \\
\hline & HCC in cirrhosis & $19.0 \%$ & \\
\hline & $\mathrm{HCC}$ in viral cirrhosis & $43.0 \%$ & \\
\hline
\end{tabular}

Data are displayed as median and range. MELD - model for end-stage liver disease; $f$ - female; $m$ - male; AlH - autoimmune hepatitis; PSC - primary sclerosing cholangitis; ALF - acute liver failure; HCC - hepatocellular carcinoma.

\section{Patient demographics}

The median age of patients was 55 (IQ: 51 to 66$), 68.3 \%(n=69)$ were male, and patients were transplanted with a median labMELD score of 14 (6 to 40 ). Over $60 \%$ of patients had a hepatocellular carcinoma (HCC) in cirrhosis with predominantly viral genesis (43\%). Other indications were alcoholic cirrhosis (10\%), viral hepatitis (14\%), acute liver failure (5\%), and autoimmune hepatitis (AIH) or primary sclerosing cholangitis (PSC) in $9 \%$ of all cases. Dialysis was necessary in $7.9 \%$ of patients prior to LT due to hepato-renal syndrome and 1 patient was on hemodialysis due to terminal renal insufficiency and listed for sequential liver and kidney transplantation (Table 1).

\section{Initiation of once daily formulation of Tacrolimus (TacOD), dosing, and trough levels}

By day 7 after LT, all patients except 3 had received TacOD in addition to the above-described immunosuppressive regimen, whereas on day 0 (day of LT) and 1 none received TacOD (day 2: 44 patients, day 3: 53 patients, day 4: 63 patients, day 5: 72 patients, day 6: 91 patients, day 7: 98 patients). TacOD dosages were increased to a median of $9 \mathrm{mg} / \mathrm{d}$ (IQ: 6 to $12 \mathrm{mg} / \mathrm{d}$ ) to achieve the intended trough levels of 5 to $8 \mathrm{ng} / \mathrm{ml}$ by day 10 , which was $5.4 \mathrm{ng} / \mathrm{ml}$ in median (IQ: 3.3 to 7.7 ) and remained stable thereafter in the investigated period. Physician compliance (adherence to the protocol using delayed introduction of TacOD) was $89 \%$. In the 12 cases of physician prescription non-compliance, the classical dosing approach as defined in the product leaflet for TacOD starting on day of transplantation was used. Additionally, for the period of 7 days until 15 days after LT, the following number of patients were outside the defined trough level range of 5 to $8 \mathrm{ng} / \mathrm{ml}$ : day $7: \mathrm{n}=6(6 \%)$, day 8: $n=9(9 \%)$, day $9: n=9(9 \%)$, day $10: n=11(11 \%)$, day 11 : $n=12(12 \%)$, day $12: n=15(15 \%)$, day $13: n=18(18 \%)$, day 14 : $n=17(17 \%)$, day $15: n=15(15 \%)$. The step-wise increase of immunosuppression and the consecutive development of TacOD trough levels are displayed in Figure 1A, 1B.

\section{Area under the curve (AUC) and regression analysis}

AUCs were calculated from CO trough levels of patients for the first 20 days after LT. AUCs analogously to CO trough levels increased from day 2 to 10 , reached a plateau of 500 to 600 $\mathrm{ng}^{*} \mathrm{~d} / \mathrm{ml}$, and remained stable thereafter $\left(\mathrm{AUC}_{\mathrm{d} 2}=77.4 \mathrm{ng} \mathrm{d}^{*} \mathrm{ml}\right.$, $\mathrm{AUC}_{\mathrm{d} 10}=528 \mathrm{ng}^{*} \mathrm{~d} / \mathrm{ml}, \mathrm{AUC}_{\mathrm{d} 11}=534 \mathrm{ng}^{*} \mathrm{~d} / \mathrm{ml}, \mathrm{AUC}_{\mathrm{d} 12}=608 \mathrm{ng}^{*} \mathrm{~d} / \mathrm{ml}$, $\mathrm{AUC}_{\mathrm{d} 13}=594 \mathrm{ng}^{*} \mathrm{~d} / \mathrm{ml}, \mathrm{AUC}_{\mathrm{d} 14}=605 \mathrm{ng}^{*} \mathrm{~d} / \mathrm{ml}, \mathrm{AUC}_{\mathrm{d} 15}=603 \mathrm{ng}^{*} \mathrm{~d} / \mathrm{ml}$, $A U C_{d 20}=364 \mathrm{ng}^{\star} \mathrm{d} / \mathrm{ml}$ ). Linear regression analysis revealed a correlation coefficient of $r=0.756$ (Figure 2 ).

\section{Adverse effects and renal function}

Ten patients (9.8\%) had impaired bowel movement during the first 10 days after LT. However, only 5 patients had slightly decreased TacOD trough levels by day 10 after LT without any clinical correlate, representing adequate resorption in the GI-tract. 

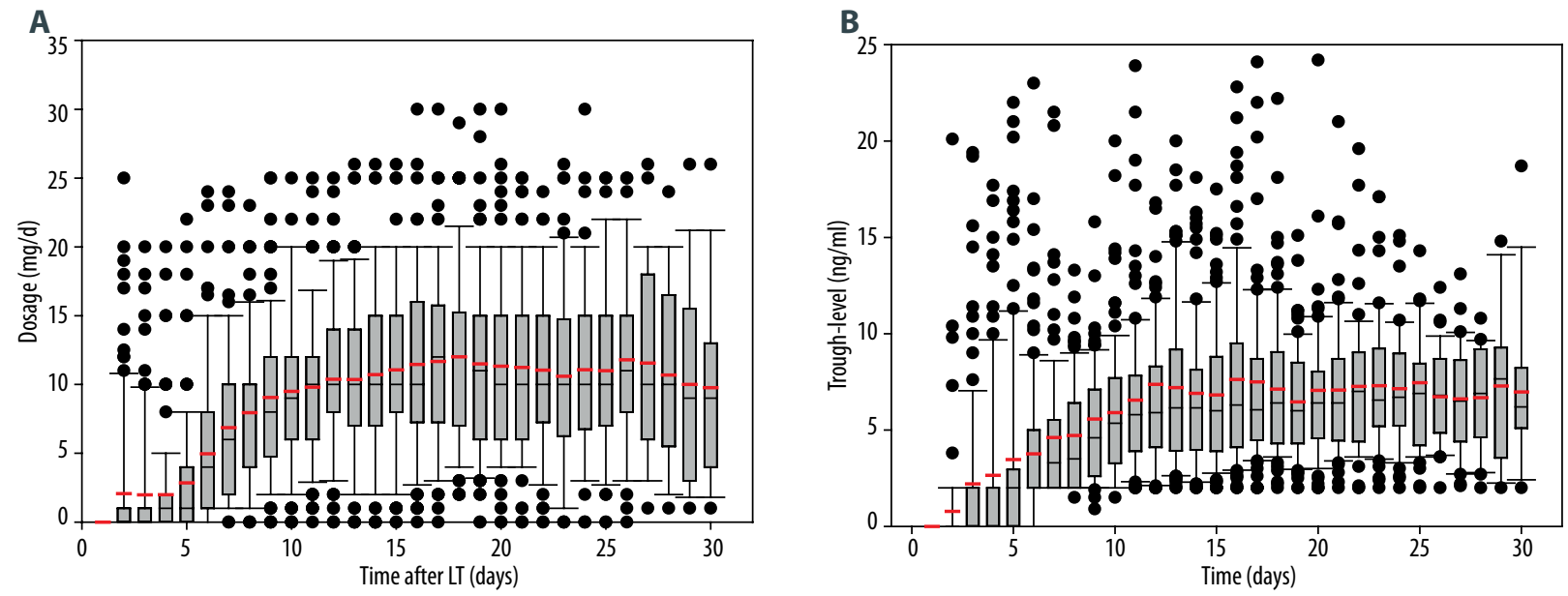

Figure 1. (A) Box plots of applied mean (red) and median (black) dosages ( $\mathrm{mg} / \mathrm{d}$ ) with $95 \%$ confidence intervals (boxes) and standard deviations (bars). Black dots represent outliers. (B) Box plots of applied mean (red) and median (black) trough levels (ng/ml) with $95 \%$ confidence intervals (boxes) and standard deviations (bars). Black dots represent outliers.

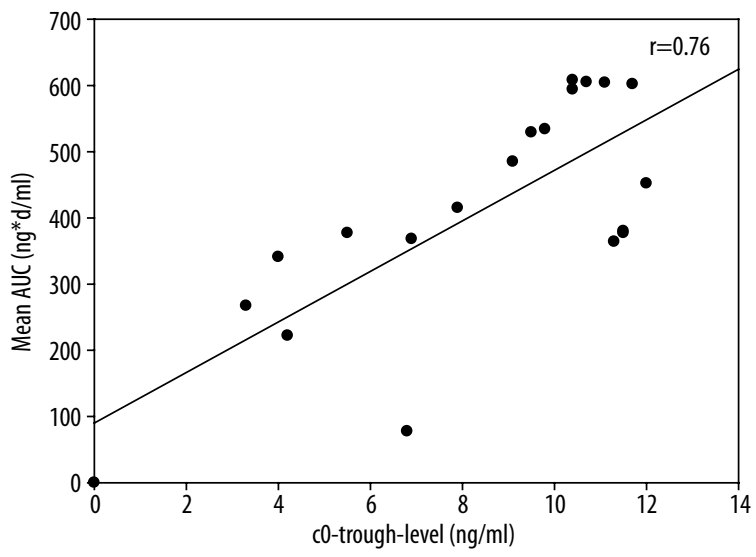

Figure 2. Correlation of mean values of area under the curves $\left(\mathrm{ng}^{*} \mathrm{~d} / \mathrm{ml}\right)$ and trough levels $(\mathrm{ng} / \mathrm{ml})$. Linear regression analysis performed for data within the first 20 days after LT.

Eighteen patients (17.8\%) developed biliary complications in the early course after LT ( $50 \%$ anastomotic strictures $/ 50 \%$ leakage), which were treated interventionally according to our local standard with ERC and stent placement. Thus, even though the enterohepatic biliary circle was impaired for a short time, 11 patients were within the intended trough level range by day 10 , with 7 patients being slightly below, but establishing an adequate trough-level by day 15 after LT, after the enterohepatic biliary circle was reestablished by interventional treatment.

Renal function was severely impaired in 13 patients (12.9\%) with post-LT anuria fulfilling the criteria for temporary renal replacement therapy, most of them (11 of 13) free from dialysis by day 14 after LT, 2 patients with renal failure prior to transplant that required ongoing therapy, but one patient $(0.9 \%)$ required hemodialysis permanently. This represents 11 patients that experienced acute renal failure after transplantation necessitating renal replacement therapy. Median creatinine values by day 10 after LT were $0.8 \mathrm{mg} / \mathrm{dl}$ (IQ: 0.6 to 1.7 ) and slightly increased by day 30 to $1.2 \mathrm{mg} / \mathrm{dl}$ (IQ: 1.0 to 1.6 ). GFR (Cockroft-Gault) was $93 \mathrm{ml} / \mathrm{min}$ (IQ: 72 to 123 ) at baseline prior to transplant, stable on day 7: $105 \mathrm{ml} / \mathrm{min}$. (IQ: 53 to 140 ) and day 10: $97 \mathrm{ml} / \mathrm{min}$. (IQ: 56 to 145 ) and decreased slightly by day $30: 84 \mathrm{ml} / \mathrm{min}$. (IQ: 56 to 114 ).

Three patients (2.8\%) had to be switched to cyclosporinebased immunosuppression due to severe neurologic adverse effects (acute psychotic syndrome, delirium episodes $(n=2)$ ), without showing elevated trough levels of TaCOD but resolution after switch to cyclosporine-based therapy. The incidence of biopsy-proven acute rejections during the first 30 days after LT was low (5 episodes in 5 patients, $4.9 \%$ ). Standard prednisolone bolus therapy (500 mg/d over 3 days) and increase of TacOD levels achieved prompt and permanent reversibility. Indeed, trough levels at the time of acute rejection were below $5 \mathrm{ng} / \mathrm{ml}$ in 4 out of 5 patients, indicating under-immunosuppression. All episodes were reversible under the abovementioned therapeutic regimen.

Hematopoietic adverse effects were also very low (3 persisting thrombopenias $<50 / \mathrm{nl}, 1$ leucopenia $<2 / \mathrm{nl}$, 2 patients with persisting anemia with hemoglobin values $<7 \mathrm{~g} / \mathrm{dl}$ ) and are represented by normal blood values in most of our patients by day 30 after LT (Table 2). Moreover, graft function (all patients with prothrombin times $>70 \%$ by day 30 after LT, 94 patients with bilirubin-levels of $2 \mathrm{mg} / \mathrm{dl}$ and lower) was satisfactory by 
Table 2. Development of lab values after liver transplantation.

\begin{tabular}{|c|c|c|c|c|c|c|}
\hline & Quick (\%) & $\begin{array}{l}\text { Bilirubin } \\
\text { (mg/dl) }\end{array}$ & $\begin{array}{l}\text { Creatinine } \\
\text { (mg/dl) }\end{array}$ & $\begin{array}{l}\text { Hemoglobin } \\
\text { (g/dl) }\end{array}$ & $\begin{array}{c}\text { WBC } \\
(\text { per } n l)\end{array}$ & $\begin{array}{l}\text { Platelets } \\
\text { (per nl) }\end{array}$ \\
\hline Baseline & $\begin{array}{c}53 \\
(42 / 68)\end{array}$ & $\begin{array}{c}2.9 \\
(1.9 / 4.9)\end{array}$ & $\begin{array}{c}0.89 \\
(0.75 / 1.15\end{array}$ & $\begin{array}{c}10.4 \\
(9.2 / 11.8)\end{array}$ & $\begin{array}{c}5.3 \\
(4.0 / 8.9)\end{array}$ & $\begin{array}{c}99 \\
(44 / 180)\end{array}$ \\
\hline Day 7 & $\begin{array}{c}78 \\
(65 / 86)\end{array}$ & $\begin{array}{c}5 \\
(2.2 / 8.6)\end{array}$ & $\begin{array}{c}0.8 \\
(0.6 / 1.3)\end{array}$ & $\begin{array}{c}9.8 \\
(9.0 / 10.5)\end{array}$ & $\begin{array}{c}5.1 \\
(3.7 / 8.1)\end{array}$ & $\begin{array}{c}55 \\
(25 / 186)\end{array}$ \\
\hline Day 10 & $\begin{array}{c}78 \\
(72 / 90)\end{array}$ & $\begin{array}{c}3.8 \\
(1.5 / 8.6)\end{array}$ & $\begin{array}{c}0.8 \\
(0.6 / 1.7)\end{array}$ & $\begin{array}{c}9.4 \\
(8.8 / 10.2)\end{array}$ & $\begin{array}{c}6.5 \\
(4.3 / 8.5)\end{array}$ & $\begin{array}{c}97 \\
(47 / 249)\end{array}$ \\
\hline Day 30 & $\begin{array}{c}71 \\
(65 / 84)\end{array}$ & $\begin{array}{c}1.8 \\
(1.1 / 4.0)\end{array}$ & $\begin{array}{c}1.2 \\
(1.0 / 1.6)\end{array}$ & $\begin{array}{c}9.1 \\
(8.6 / 10.1)\end{array}$ & $\begin{array}{c}7.9 \\
(5.2 / 11.6)\end{array}$ & $\begin{array}{c}141 \\
(75 / 335)\end{array}$ \\
\hline
\end{tabular}

Data are displayed as median and IQ (interquartile range). Quick - prothrombin time; WBC - white blood cells.

day 30 after LT, with no retransplantation and no deaths within 30 days after transplantation.

\section{Subgroup-analysis}

In the analyzed subgroup of patients with HCC $(n=63)$ vs. nonHCC $(n=38)$ indications, there were differences in labMELD scores: 12 (range: 6 to 32; IQ: 8 to 15) vs. 21 (range: 6 to 40; IQ: 15 to 33), the number of dialysis prior to transplant: $6 \mathrm{vs}$. 2 , and a difference in renal function from baseline: $80 \mathrm{ml} / \mathrm{min}$. (IQ: 61 to 103) vs. $96 \mathrm{ml} / \mathrm{min}$. (IQ: 79 to 128 ), $p=0.003$, that was not present at day 30: $63 \mathrm{ml} / \mathrm{min}$. (IQ: 49 to 101) vs. 85 $\mathrm{ml} / \mathrm{min}$. (IQ: 78 to 12 ), $\mathrm{p}=0.133$. The completed introduction of TacOD was slightly later in the non-HCC group (day 8 vs. day 7), whereas on day 4,20 of 38 patients (53\%) in the non-HCC-group but only 20 out of 63 (30\%) were not yet on TacOD. However, trough levels were not significantly different between groups.

In the analyzed subgroup of patients with labMELD $\geq 25 \quad(n=21)$ vs. labMELD $<25(\mathrm{n}=80)$, the distribution of pretransplant dialysis was 6 vs. 2. There was a significant difference in GFR (CockroftGault) at baseline: $66 \mathrm{ml} / \mathrm{min}$ (IQ: 33 to 81) vs. $99 \mathrm{ml} / \mathrm{min}$. (80 to 124$), \mathrm{p}<0.001$, at day $7: 58 \mathrm{ml} / \mathrm{min}(\mathrm{IQ}: 36$ to 177$)$ vs. 116 (IQ: 69 to 181 ), $p=0.003$ and day 10: $64 \mathrm{ml} / \mathrm{min}$. (IQ: 39 to 131) vs. 106 (IQ: 63 to 148), $p=0.045$. This difference decreased until day 30 with a remaining trend: $61 \mathrm{ml} / \mathrm{min}$. (IQ: 44 to 88 ) vs. 85 $\mathrm{ml} / \mathrm{min}$ (62 to 106), $\mathrm{p}=0.086$. On day 4,10 out of 21 (48\%) vs. 10 out of 80 (12\%) were not on TacOD. Nonetheless, there were no significant differences in trough levels at a later time-point.

\section{Discussion}

This is the first report of an amended and simple method of dosing TaCOD in patients undergoing LT. Our data suggest that this bottom-up strategy is safe and efficient. Furthermore, the approximately 10 -fold lower initial dosing avoids the requirement for top-down dosing after the first days due to overshooting trough levels, as shown in the pharmacokinetic report by Fischer et al. or other reports with an abrupt establishment of rather high levels of CNI [13,14]. Additionally, the strategy of delayed bottom-up introduction of TacOD creates a slowly rising curve of trough levels and titration to the targeted trough level of 5 to $8 \mathrm{ng} / \mathrm{ml}$. The amended method of dosing thus represents a good compromise in providing adequate immunosuppressive protection by otherwise low-dose immunosuppression, avoiding early adverse effects of $\mathrm{CNI}$ and an acceptably low incidence of BPAR (4.9\%).

The strategy of introducing TacOD starting with $1 \mathrm{mg} / \mathrm{d}$ and doubling the dosage until the targeted trough level range is reached is easily transferable into a clinical setting. It is a simple algorithm that can be followed by younger and less experienced professionals in the adjustment of immunosuppressive drugs in the postoperative course. Nonetheless, our data show a considerable rate of approximately $10 \%$ of non-adherence to the proposed strategy, even within our own department. In the early period of establishing the new algorithm, the old method of dosing repeatedly was applied, resulting in considerably higher dosages and over-immunosuppression of some patients. This non-adherence was completely eliminated, but reflects a common problem in the communication between health care professionals, which is reported at up to $35 \%$ $[15,16]$. Nonetheless, data were left in the analysis to give a valid picture of clinical reality and obstacles that have to be overcome in establishing new treatment pathways and strategies.

Adverse effects under TacOD were mild and in agreement with published data from other series [14]. Notably, we did not see neurologic adverse effects due to over-immunosuppression, although 3 patients were switched to cyclosporine due to severe neurologic adverse effects within the target trough levels [17]. Furthermore, biopsy-proven acute rejections were few and in good agreement with published data, like the OPTN (Organ Procurement and Transplantation Network) report of 2011 with an early incidence of $5 \%$ within the first month after 
LT [18]. The stable early renal function without deterioration under delayed and bottom-up immunosuppressive treatment which we observed was also in good agreement with the data from Neuberger et al. from the ELITE-Respect study in which the delayed reduced Tacrolimus arm showed best results for renal function at 1 year after LT [11].

\section{Conclusions}

Taking into account the low number and incidence of adverse effects under the new bottom-up, amended, and simple dosing

\section{References:}

1. First MR: First clinical experience with the new once-daily formulation of tacrolimus. Ther Drug Monit, 2008; 30: 159-66

2. Barraclough KA, Isbel NM, Johnson DW et al: Once- versus twice-daily tacrolimus: are the formulations truly equivalent? Drugs, 2011; 71: 1561-77

3. Weiler $\mathrm{N}$ et al: Tacrolimus effects and side effects after liver transplantation: is there a difference between immediate and extended release? Transplant Proc, 2013; 45: 2321-25

4. Alloway RR, Eckhoff DE, Washburn WK, Teperman LW: Conversion from twice daily tacrolimus capsules to once daily extended-release tacrolimus (LCPTacro): phase 2 trial of stable liver transplant recipients. Liver Transplant, 2014; 20: 564-75

5. Stifft F, Stolk LML, Undre N et al: Lower variability in 24-hour exposure during once-daily compared to twice-daily tacrolimus formulation in kidney transplantation. Transplantation, 2014; 97: 775-80

6. Tsuchiya $\mathrm{T}$, Ishida $\mathrm{H}$, Tanabe $\mathrm{T}$ et al: Comparison of pharmacokinetics and pathology for low-dose tacrolimus once-daily and twice-daily in living kidney transplantation: prospective trial in once-daily versus twice-daily tacrolimus. Transplantation, 2013; 96: 198-204

7. Osterlee A, Rahmel A: Eurotransplant Annual Report 2011. www.eurotransplant.nl

8. Sharma P, Welch K, Eikstadt R et al: Renal outcomes after liver transplantation in the model for end-stage liver disease era. Liver Transplant, 2009; 15: $1142-48$

9. Farkas SA, Schnitzbauer AA, Kirchner G et al: Calcineurin inhibitor minimization protocols in liver transplantation. Transpl Int, 2009; 22(1): 49-60 regimen, and achieving stable trough levels within the defined target until day 10 after LT, our new treatment algorithm appears to be safe and efficient and is a good and clinically relevant alternative to the proposed dosing regimen of the marketing authorization holder.

\section{Conflict of Interest}

The authors of this manuscript have conflicts of interest to disclose as described by the American Journal of Transplantation: all authors declare that they have received travel support by Astellas Pharmaceutics to scientific meetings.

10. Schnitzbauer AA, Doenecke A, Sothmann JL et al: Improved outcome after 'bottom-up' immunosuppression in liver transplant recipients with preoperative renal impairment. Eur Surg, 2010; 45: 356-67

11. Neuberger JM, Mamelok RD, Neuhaus $P$ et al: Delayed introduction of reduced-dose tacrolimus, and renal function in liver transplantation: the 'ReSpECT' study. Am J Transplant, 2009; 9: 327-36

12. Schnitzbauer AA, Scherer MN, Rochon J et al: Study protocol: a pilot study to determine the safety and efficacy of induction-therapy, de novo MPA and delayed mTOR-inhibition in liver transplant recipients with impaired renal function. PATRON-study. BMC Nephrol, 2010; 11, 24

13. Fischer L, Trunečka P, Gridelli B et al: Pharmacokinetics for once-daily versus twice-daily tacrolimus formulations in de novo liver transplantation: a randomized, open-label trial. Liver Transplant, 2011; 17: 167-77

14. Trunečka $P$, Boillot $O$, Seehofer $D$ et al: Once-daily prolonged-release tacrolimus (ADVAGRAF) versus twice-daily tacrolimus (PROGRAF) in liver transplantation. Am J Transplant, 2010; 10: 2313-23

15. Farup PG, Blix I, Førre S et al: What causes treatment failure - the patient primary care, secondary care or inadequate interaction in the health services? BMC Health Serv Res, 2011; 11: 111

16. Spinewine A, Claeys C, Foulon V, Chevalier P: Approaches for improving continuity of care in medication management: a systematic review. Int I Qual Health Care, 2013; 25: 403-17

17. Platz KP, Mueller AR, Jonas $S$ et al: Toxicity versus rejection - or why conversions between cyclosporine A and FK506 were performed after liver transplantation. Clin Transplant, 1995; 9: 146-54

18. Kim WR, Stock PG, Smith JM et al: OPTN/SRTR 2011 Annual Data Report: liver. Am J Transplant, 2013; 13(Suppl.1): 73-102 